Article

\title{
Combined Effect of Pressure-Assisted Thermal Processing and Antioxidants on the Retention of Conjugated Linoleic Acid in Milk
}

\section{Sergio I. Martinez-Monteagudo and Marleny D.A. Saldaña*}

Department of Agricultural, Food and Nutritional Science, University of Alberta, Edmonton, AB T6G 2P5, Canada; E-Mail: marleny.saldana@ualberta.ca

* Author to whom correspondence should be addressed; E-Mail: marleny.saldana@ ualberta.ca; Tel.: +1-780-492-8018; Fax: +1-780-492-8914.

Academic Editor: Carl Joseph Schaschke

Received: 21 January 2015 / Accepted: 28 March 2015 / Published: 14 April 2015

\begin{abstract}
The effect of pressure-assisted thermal processing (PATP) in combination with seven synthetic antioxidants was evaluated on the retention of conjugated linoleic acid (CLA) in enriched milk. Milk rich in CLA was first saturated with oxygen, followed by the addition of either catechin, cysteine, ascorbic acid, tannic acid, gallic acid, caffeic acid or $p$-coumaric acid (500 $\mathrm{mg} \mathrm{kg}^{-1}$ untreated milk). Samples were treated at $600 \mathrm{MPa}$ and $120^{\circ} \mathrm{C}$ up to $15 \mathrm{~min}$ of holding time. During PATP, CLA not only oxidized at a slower rate, but also less oxygen was consumed compared to the control $\left(0.1 \mathrm{MPa}\right.$ and $\left.120{ }^{\circ} \mathrm{C}\right)$. In addition, phenolic antioxidants were able to quench dissolved oxygen in samples treated with PATP. For those samples added with gallic acid and catechin, $85 \%$ and $75 \%$ of the CLA was retained after $15 \mathrm{~min}$ of holding time at $600 \mathrm{MPa}$ and $120{ }^{\circ} \mathrm{C}$, respectively. The retention of CLA was enhanced by the application of PATP in combination with gallic acid.
\end{abstract}

Keywords: antioxidants; conjugated linoleic acid; dissolved oxygen; pressure-assisted thermal processing; phenolics 


\section{Introduction}

Pressure-assisted thermal processing (PATP) has become a valuable alternative to traditional thermal treatments. Although sterilized products treated with PATP have not been commercialized yet, this technology has the potential to deliver a variety of novel products, and its further implementation at the industrial level is expected in the short to medium term [1].

There are three important characteristics of PATP. First, the rise in the sample temperature due to the heat of compression is used to reach the target or sterilization temperature, reducing the thermal damage that takes place in traditional sterilization processes [2]. Second, pressure reduces interatomic distance, affecting interactions, the bond energy which is distance dependent. Such interactions are van der Waals forces, electrostatic forces, hydrogen bonding and hydrophobic interactions of proteins. In contrast, covalent bonds are unlikely to be affected by pressure, because the bonding distance can be hardly further compressed [3]. This has been the main hypothesis in preserving the biological activity of functional compounds, such as ascorbic acid [4,5], folates [6,7], anthocyanins [8], lycopene [9] and conjugated linoleic acid [10]. Finally, the rate of a chemical reaction can be increased or decreased by pressure, according to whether the molar volume of the intermediate state (activated complex) is less or more

voluminous. For a chemical reaction, the effect of pressure favours those reactions with a negative reaction volume and those reaction pathways with a negative activation volume [3].

Some authors have suggested that PATP can be used to produce superior quality products in cases where the traditional thermal treatments have failed to deliver high-quality products, such as egg-based and milk-based products, baby foods, desserts, gravies, soups and sauces [3,11].

In an effort to develop high-value milk products, various investigations have highlighted the health benefits of conjugated linoleic acid (CLA), a bioactive component naturally found in milk fat [12]. Unfortunately, CLA in milk suffers significant losses during heat treatment, including ultra-high temperature (UHT), as discussed elsewhere [13-16]. Interestingly, CLA was retained up to 90\% when catechin, a potent antioxidant, was added at $1 \mathrm{~g}$ per $\mathrm{kg}$ of milk, regardless of the processing conditions used (60-120 ${ }^{\circ} \mathrm{C}$ and 100-600 MPa) [17]. These findings suggest that the use of antioxidants can enhance the retention of CLA in milk. However, their effectiveness and the way in which they capture free radicals or react with the dissolved oxygen to retard the free radical reactions have not been studied under PATP conditions. Understanding the antioxidant mechanisms under PATP conditions is important for product development. Thus, the objective of this study was to evaluate the combined effect of PATP and seven commonly-used antioxidants on the retention of CLA in milk.

\section{Experimental Section}

\subsection{Obtaining CLA-Enriched Milk and Sample Preparation}

Milk rich in CLA was obtained from the Dairy Research and Technology Centre at the University of Alberta (Edmonton, AB, Canada), following the protocol provided elsewhere [18]. Briefly, 12 lactating Holstein cows were first fed with a control diet for 3 days. Then, the cows were fed for 16 days with a diet supplemented with sunflower ground seed at $6 \%$ of dry matter. The diet consists of $60 \%$ forage and $40 \%$ concentrate. Cows were housed in tie stalls, and water was available at all times. The CLA-enriched milk was stored at $-20{ }^{\circ} \mathrm{C}$ until needed. Prior to the PATP experiments, the CLA-enriched milk was 
thawed with running water at room temperature. Then, the milk rich in CLA was saturated with oxygen by bubbling oxygen for $45 \mathrm{~min}$ at room temperature. After that, five hundred milligrams of either catechin (CAT), cysteine (Cyst), ascorbic acid (AA), tannic acid (TAN), gallic acid (GA), caffeic acid (CAF) or $p$-coumaric acid (CUM) were added per one $\mathrm{kg}$ of untreated milk. All antioxidants used were reagent grade and were purchased from Sigma-Aldrich (Saint Louis, MO, USA). The antioxidants were dissolved using a bench homogenizer Diax 900 (Rose Scientific Ltd., Edmonton, AB, Canada).

\subsection{Pressure-Assisted Thermal Processing}

PATP experiments were carried out in 3-mL polypropylene tubes (Cryogenic vial, Fisher Scientific, Edmonton, AB, Canada). The tubes were filled with either raw CLA-enriched milk or CLA-enriched milk added with an antioxidant, capped and shaken before immersion in an oil bath at $102{ }^{\circ} \mathrm{C}$. The preheating temperature was fixed, considering that the temperature of milk rises $3{ }^{\circ} \mathrm{C}$ per $100 \mathrm{MPa}$ [19]. After $2 \mathrm{~min}$, the pre-heated samples were transferred to the high pressure multivessel system (Apparatus U111 Unipress, Warszawa, Poland), where the vessels were already heated at $120{ }^{\circ} \mathrm{C}$. The vessels were heated with a thermostat (Lauda Proline RP 855 Low Temperature, Lauda-Königshofen, Germany) using propylene glycol, which was also the pressure transmission fluid. The unit has four high pressure vessels with an internal volume of $8 \mathrm{~mL}$. The temperature of the transmission fluid was recorded using a Type $\mathrm{K}$ thermocouple located at the bottom of each vessel. Then, the samples were pressurized at $600 \mathrm{MPa}$ using a rate of $10 \mathrm{MPa} \mathrm{s}^{-1}$. Once $600 \mathrm{MPa}$ was reached, the samples were held for $1,5,10$ and $15 \mathrm{~min}$. At the end of the holding time, the vessels were decompressed, and the samples were removed immediately from the high pressure vessels and cooled down with ice to avoid any further CLA degradation. For the control treatments, samples of raw CLA-milk in closed polypropylene tubes were pre-heated at $102{ }^{\circ} \mathrm{C}$ and subsequently transferred to an oil bath at $120{ }^{\circ} \mathrm{C}$ to imitate the PATP experimental run. For simplicity, the control treatments are referred to as samples treated at $0.1 \mathrm{MPa}$. PATP-treated and control samples were kept at $-18{ }^{\circ} \mathrm{C}$ until further analysis. An additional set of experiments was conducted using different concentrations of CAT and GA (0, 100, 200, 300 and $500 \mathrm{mg} \mathrm{kg}^{-1}$ ). The samples were treated at $120^{\circ} \mathrm{C}$ for $15 \mathrm{~min}$ at either 0.1 or $600 \mathrm{MPa}$. The CLA was expressed in terms of normalized $\left(\mathrm{CLA}_{\mathrm{t}} / \mathrm{CLA}_{\mathrm{o}}\right.$ ) retained fraction from 0 to 1 . The experimental protocol has been validated for kinetics studies elsewhere [10]. All experimental data were obtained in triplicate.

\subsection{Analytical Determinations}

\subsubsection{CLA Determination}

The CLA content was determined by gas chromatography using a 100-m SP-2560 fused-silica capillary column, adopting the methodology previously described elsewhere [20]. The CLA content measured by the GC represented the total CLA.

\subsubsection{Dissolved Oxygen}

The dissolved oxygen $\left(\mathrm{DO}_{2}\right)$ in milk was measured using an oxygen meter $(\mathrm{OM}-4$, Microelectrodes, Inc., Bedford, NH, USA). The oxygen meter was calibrated using a two-point calibration (0\% and 100\% of saturation). The electrode was immersed in $0 \%$ solution obtained by boiled and cooled water under 
nitrogen flushing. The $100 \%$ of saturation solution was obtained by bubbling oxygen for 45 min at room temperature in $500 \mathrm{~mL}$ of enriched milk. At each experimental point, the electrode was allowed to stabilize to the sample temperature before the $\mathrm{DO}_{2}$ measurement was recorded. The measurements of $\mathrm{DO}_{2}$ were performed in duplicate.

\subsection{Data Analysis}

\subsubsection{Retention of CLA}

The retained CLA in the presence of oxygen during processing was described according to reaction as follows:

$$
\mathrm{CLA}+\mathrm{O}_{2} \stackrel{k_{1}}{\rightarrow} \text { oxidation products }
$$

where $k_{1}$ is the oxidation rate constant $\left(\mathrm{min}^{-1}\right)$ for each antioxidant, the $k_{1}$ value was obtained by solving the following differential equation:

$$
\frac{d \mathrm{CLA}}{d t}=\frac{d \mathrm{O}_{2}}{d t}=-k_{1} \cdot \mathrm{CLA} \cdot \mathrm{O}_{2}
$$

\subsubsection{Quenching Ability}

An additional set of experiments was performed to determine the quenching ability of phenolic antioxidants in milk treated at $120^{\circ} \mathrm{C}$ and $600 \mathrm{MPa}$. Quenching oxygen by phenolic antioxidants was described by a bimolecular mechanism that follows:

$$
\mathrm{O}_{2}+\mathrm{Q} \stackrel{k_{2}}{\rightarrow} \text { products }
$$

where $\mathrm{Q}$ is the quenching agent or phenolic antioxidant; and $k_{2}$ is the apparent quenching rate constant $\left(\min ^{-1}\right)$. Total phenolic content was considered as the quenching agent, and it was determined by the Folin-Ciocalteu method reported elsewhere [21]. Then, Equations (2)-(4) were solved simultaneously to obtain $k_{1}$ and $k_{2}$ values.

$$
\begin{gathered}
\frac{d \mathrm{CLA}}{d t}=-k_{1} \cdot \mathrm{CLA} \cdot \mathrm{O}_{2} \\
\frac{d \mathrm{O}_{2}}{d t}=-k_{1} \cdot \mathrm{CLA} \cdot \mathrm{O}_{2}-k_{2} \cdot \mathrm{O}_{2} \cdot \mathrm{Q} \\
\frac{d \mathrm{Q}}{d t}=-k_{2} \cdot \mathrm{O}_{2} \cdot \mathrm{Q}
\end{gathered}
$$

The differential equations were solved using DYNAFIT (BioKin Ltd., Madison, WI, USA, www.biokin.com/dynafit).

\section{Results and Discussion}

\subsection{Pressure, Temperature and Time History}

Figure 1 shows the pressure and temperature history during PATP of CLA-enriched milk treated at $600 \mathrm{MPa}$ and $120^{\circ} \mathrm{C}$ for $15 \mathrm{~min}$ of holding time. The time needed to insert the preheated sample $\left(102{ }^{\circ} \mathrm{C}\right)$, adjust the transmission fluid volume and close the high pressure vessel was considered as the 
loading time $\left(t_{1}\right)$. Likewise, the time required to reach isothermal and isobaric conditions was labelled as the compression time $\left(t_{\mathrm{c}}\right)$. The temperature of the transmission fluid dropped $13{ }^{\circ} \mathrm{C}$ during compression, because the temperature of the pressurizing fluid that comes from the intensifier was lower $\left(\sim 75^{\circ} \mathrm{C}\right)$ compared to the fluid temperature inside the vessel $\left(120^{\circ} \mathrm{C}\right)$. The temperature of the sample and the medium increased due to adiabatic heating, reaching a final temperature of $120^{\circ} \mathrm{C}$. The point where both isothermal and isobaric conditions have been reached was considered the start of the holding time $\left(t_{\mathrm{h}}\right)$. It can be assumed that the temperature of the transmission fluid, sample and vessel are the same $\left(120{ }^{\circ} \mathrm{C}\right)$ during the holding time. Knowledge of the temperature and pressure history during PATP is needed for a correct interpretation of the experimental findings. The reduction of CLA can be attributed to a combination of pressure, temperature and time rather than temperature itself. The processing conditions of $600 \mathrm{MPa}$ and $120^{\circ} \mathrm{C}$ for at least $5 \mathrm{~min}$ were enough to inactivate seven-log of Bacillus amyloliquefaciens in CLA-enriched milk and to inactivate $99.9 \%$ of alkaline phosphatase [22].

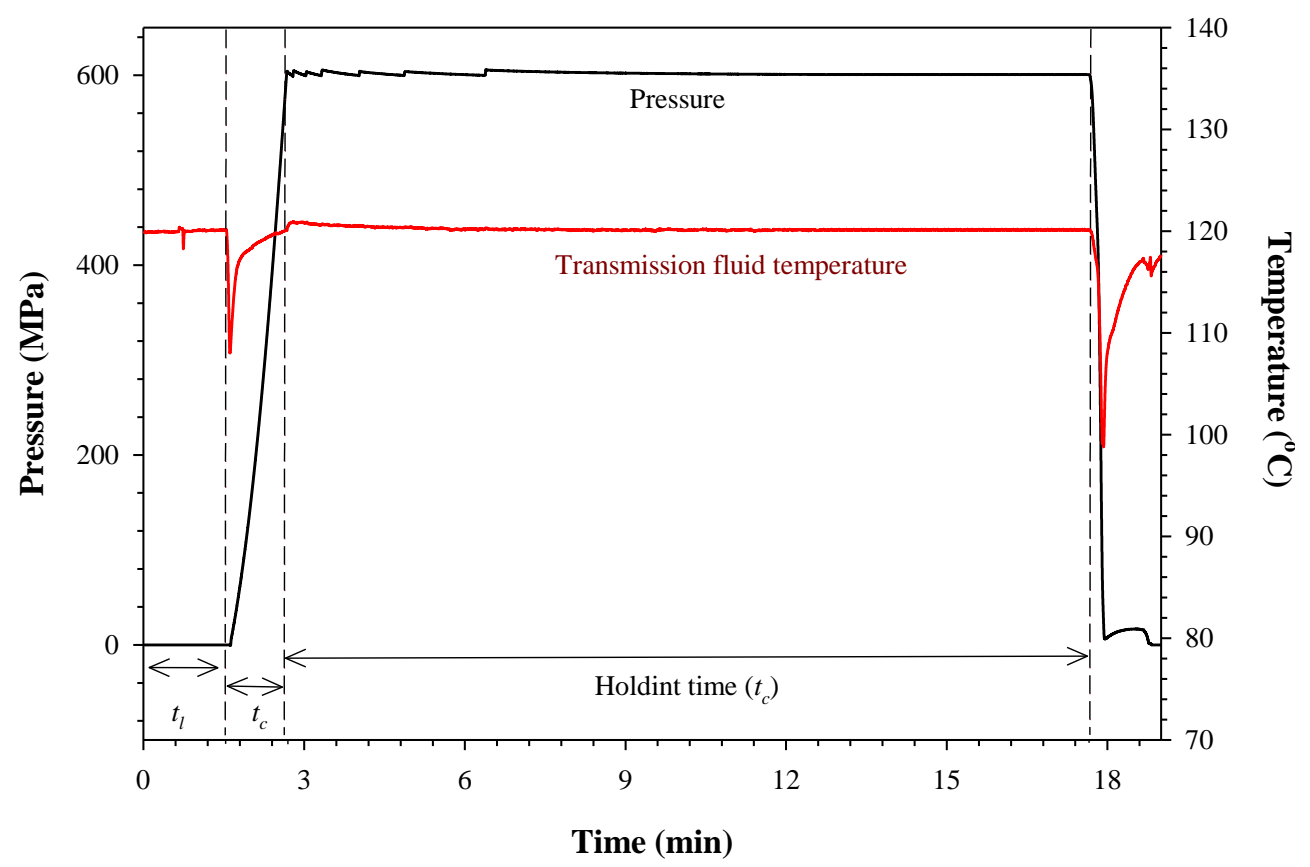

Figure 1. Typical pressure, temperature and time history during pressure-assisted thermal processing of conjugated linoleic acid (CLA)-enriched milk treated at $600 \mathrm{MPa} / 120{ }^{\circ} \mathrm{C}(t$, loading time; $t_{\mathrm{c}}$, compression time; $t_{\mathrm{h}}$, holding time).

\subsection{CLA-Enriched Milk}

Milk saturated with oxygen and treated at $120{ }^{\circ} \mathrm{C}$ for up to $15 \mathrm{~min}$ was used to induce oxidation and therefore to evaluate the role of different antioxidants. Figure $2 \mathrm{a}$ shows the CLA changes in CLA-enriched milk treated at $0.1 \mathrm{MPa} / 120^{\circ} \mathrm{C}$ or $600 \mathrm{MPa} / 120^{\circ} \mathrm{C}$ up to $15 \mathrm{~min}$. At $0.1 \mathrm{MPa}$, the retained fractions of CLA were 0.44 (44\%) and 0.35 (35\%) after 10 and $15 \mathrm{~min}$, respectively. Similarly, Martinez-Monteagudo and Saldaña [15] reported that 15\%-21\% of CLA was retained in CLA-enriched milk heated at $120{ }^{\circ} \mathrm{C} / 0.1 \mathrm{MPa}$. The difference in the retained fractions can be attributed to the different batch milk samples used. In milk fortified with CLA (2\% of CLA in the total fat), the retained CLA ranged from $79 \%$ to $95 \%$, depending on the processing conditions $\left(125-145{ }^{\circ} \mathrm{C} / 2-20 \mathrm{~s}\right)[13,14]$. The 
high temperature used $\left(120^{\circ} \mathrm{C}\right)$ induces oxidation of CLA via the formation of free radicals through thermolysis. In addition, the dissolved oxygen reacts with oxygen species to form oxygen radicals, such as hydroxyl (HO•), peroxyl (ROO•) and hydroperoxyl (HOO•). These radicals can easily act as initiators for the oxidation of CLA. This is in agreement with the changes in $\mathrm{DO}_{2}$ observed in Figure $2 \mathrm{~b}$. At $0.1 \mathrm{MPa}$, the remaining fractions of $\mathrm{DO}_{2}$ after 10 and 15 min were 0.61 and 0.37 , respectively. At $600 \mathrm{MPa}$, CLA was remarkably stable compared to the control treatment at $0.1 \mathrm{MPa}$, retaining 0.76 and 0.74 after 10 and $15 \mathrm{~min}$, respectively. Based on these results, pressure may influence the reaction mechanism by which CLA is oxidized. Experimental data from the literature showed that thermal decomposition through homolysis of single bond and two-bond scission is delayed by the application of pressure up to $395 \mathrm{MPa}$ at $100{ }^{\circ} \mathrm{C}[23,24]$. A deceleration in the decomposition or homolysis of unsaturated fatty acids might result in a protective effect of the CLA.
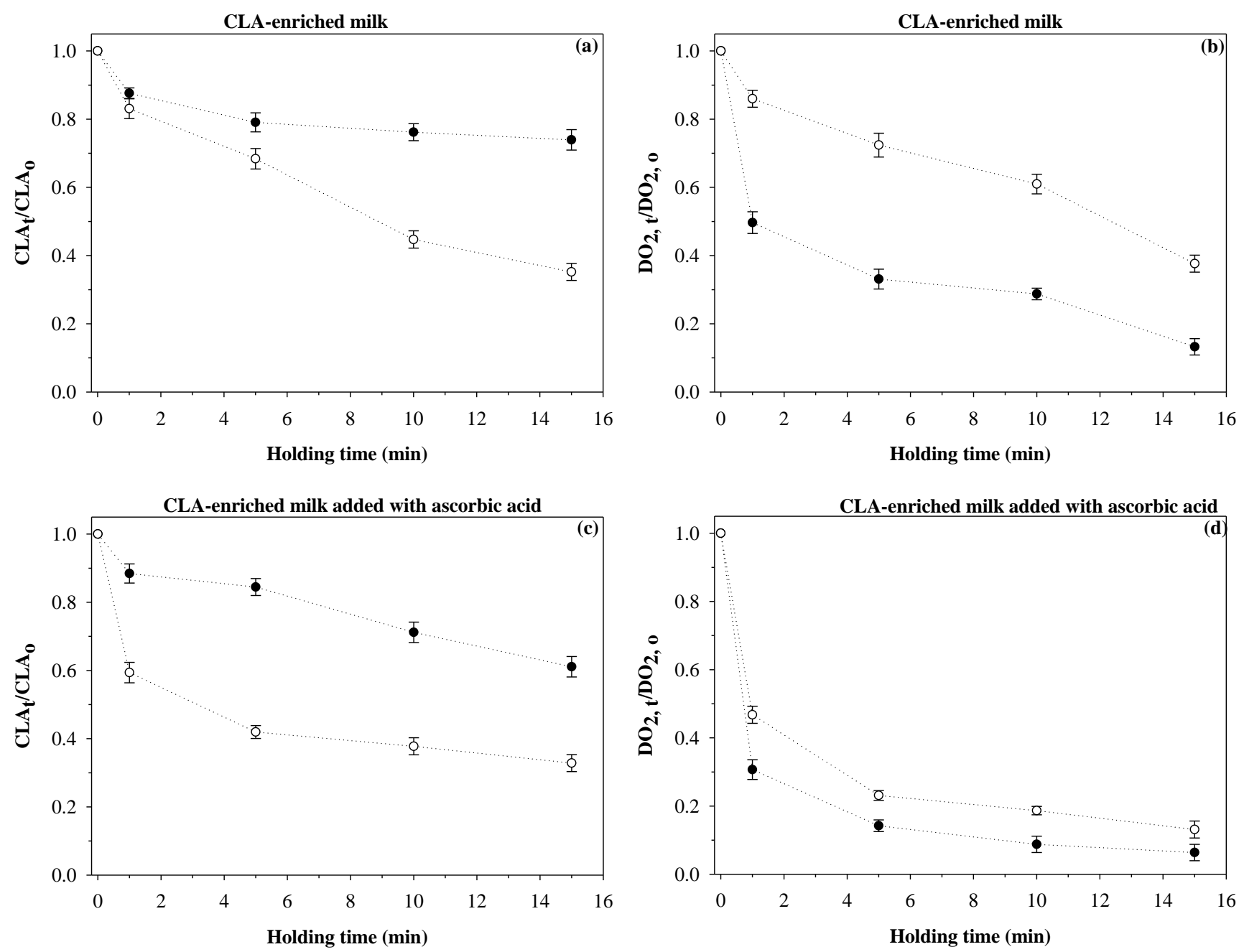

Figure 2. Changes in conjugated linoleic acid (CLA) and dissolved oxygen $\left(\mathrm{DO}_{2}\right)$ in CLA-enriched milk treated at $120^{\circ} \mathrm{C}$ and either $600 \mathrm{MPa}(\bullet)$ or $0.1 \mathrm{MPa}(\mathrm{\circ})$.

Figure $2 \mathrm{~b}$ shows the normalized $\mathrm{DO}_{2}$ in CLA-enriched milk treated at PATP. The remaining fractions of $\mathrm{DO}_{2}$ at $600 \mathrm{MPa} / 120^{\circ} \mathrm{C}$ were 0.28 and 0.13 after 10 and $15 \mathrm{~min}$, respectively. Table 1 shows the $k_{l}$ values calculated from Equations (1) and (2). The $k_{l}$ value accounts for two contributions, CLA reduction and $\mathrm{DO}_{2}$ consumption, and its determination can be used to infer possible reaction mechanisms. The 
$k_{1}$ value for milk was lower at $600 \mathrm{MPa} / 120{ }^{\circ} \mathrm{C}$ compared with that at $0.1 \mathrm{MPa} / 120{ }^{\circ} \mathrm{C}(0.059$ and $0.091 \mathrm{~min}^{-1}$, respectively), indicating that pressure had a protective effect. Similarly, Martinez-Monteagudo and Saldaña [10] showed that the combination of $600 \mathrm{MPa} / 120{ }^{\circ} \mathrm{C}$ induces isomerisation rather than oxidation of CLA in milk rich in CLA. Isomerization only changes the isomer distribution of CLA without changing the total amount of CLA. In this study, total CLA was quantified, but milk fat contains over 20 different CLA isomers for which cis-9/trans-11 is the predominant isomer ( $\geq 85 \%)$. There are two possible mechanisms for the isomerization of CLA, and the predominant mechanism depends on the oxygen content [25]. The first mechanism consists of the migration of the double bond, known as sigmatropic molecular rearrangements, which is induced by temperature in the absence of oxygen. The second mechanism occurs in the presence of oxygen through free radical chain reaction, similar to the initiation step of the autoxidation of linoleic acid (C18:2) [26]. Interestingly, the initiation and propagation steps of free radical polymerization are indeed accelerated by pressure [27]. Therefore, it is reasonable to hypothesize that isomerization of CLA through the free radical mechanism is the predominant reaction at $600 \mathrm{MPa} / 120^{\circ} \mathrm{C}$. Contrary to this, oxidation of CLA rather than isomerization is the predominant reaction at $0.1 \mathrm{MPa} / 120^{\circ} \mathrm{C}$.

Table 1. Oxidation rate constant $\left(k_{1}, \mathrm{~min}^{-1}\right)$ of CLA-enriched milk treated at $120{ }^{\circ} \mathrm{C}$ and either 600 or $0.1 \mathrm{MPa}$.

\begin{tabular}{ccccc}
\hline \multirow{2}{*}{ Antioxidant } & \multicolumn{2}{c}{$\mathbf{6 0 0} \mathbf{~ M P a}$} & \multicolumn{2}{c}{$\mathbf{0 . 1} \mathbf{~ M P a}$} \\
\cline { 2 - 5 } & $\boldsymbol{k}_{\boldsymbol{l}}, \mathbf{m i n}^{-\mathbf{1}}$ & $\mathbf{9 5 \%} \mathbf{C I}$ & $\boldsymbol{k}_{\boldsymbol{l}}, \mathbf{~ m i n}^{-\mathbf{1}}$ & $\mathbf{9 5 \%} \mathbf{C I}$ \\
\hline Milk & 0.059 & 0.006 & 0.091 & 0.010 \\
Ascorbic acid & 0.081 & 0.009 & 0.366 & 0.050 \\
Cysteine & 0.030 & 0.005 & 0.194 & 0.051 \\
Caffeic acid & 0.041 & 0.015 & 0.078 & 0.020 \\
Catechin & 0.051 & 0.009 & 0.139 & 0.015 \\
Gallic acid & 0.092 & 0.018 & 0.150 & 0.036 \\
-Coumaric acid & 0.042 & 0.011 & 0.118 & 0.011 \\
Tannic acid & 0.069 & 0.019 & 0.084 & 0.017 \\
\hline
\end{tabular}

$k_{l}$ is obtained by solving Equations (1) and (2); 95\% CI, 95\% confidence interval.

\subsection{Ascorbic Acid}

Changes in CLA content in enriched milk added with AA and treated at sterilization conditions are shown in Figure 2c. The retained CLA contents after 10 and $15 \mathrm{~min}$ were 0.37 and 0.32 at $0.1 \mathrm{MPa} / 120{ }^{\circ} \mathrm{C}$, respectively. After $15 \mathrm{~min}$, the retained CLA was similar to that in CLA-enriched milk without antioxidant addition ( $\sim 0.35$; Figure $2 \mathrm{a}$ ). The processing conditions of $120^{\circ} \mathrm{C}$ and up to $15 \mathrm{~min}$ are rather severe and could oxidize the ascorbic acid, causing it to lose its antioxidant activity. In UHT milk, ascorbic acid is lost by up to $50 \%$, depending on the severity of the treatment time $\left(135-150{ }^{\circ} \mathrm{C} / 4 \mathrm{~s}\right)$ [28]. On the other hand, the combination of AA and a pressure of $600 \mathrm{MPa}$ at $120{ }^{\circ} \mathrm{C}$ enhanced the retention of CLA (0.61) after $15 \mathrm{~min}$ of treatment compared with the treatment at $0.1 \mathrm{MPa} / 120{ }^{\circ} \mathrm{C}(0.32)$ and milk without added antioxidant $(0.35)$. One possible explanation is that pressure protects the $\mathrm{AA}$, which further reacts with $\mathrm{DO}_{2}$ and free radicals. AA was used to inhibit the formation of aldehydes in milk treated at $655 \mathrm{MPa}$ and $75{ }^{\circ} \mathrm{C}$ for $5 \mathrm{~min}$ [29]. An investigation on the 
retention of AA in pressurized phosphate buffer systems showed that AA remained unchanged at a moderate temperature of $50{ }^{\circ} \mathrm{C}$ and $850 \mathrm{MPa}$, while at a higher temperature of $80{ }^{\circ} \mathrm{C}$ and $850 \mathrm{MPa}$, the AA degradation became notorious. More importantly, AA can be used to enhance the stability of folates in pressurized orange and tomato juices [4]. Another investigation showed that the combination of $700 \mathrm{MPa}$ and $110{ }^{\circ} \mathrm{C}$ accelerated the degradation rate of ascorbic acid up to 20 times in raspberries [5]. These variations can be attributed to differences in the food matrix, processing conditions and dissolved oxygen.

The changes in $\mathrm{DO}_{2}$ in milk with added $\mathrm{AA}$ are shown in Figure $2 \mathrm{~d}$. For those samples treated at $0.1 \mathrm{MPa}$, the $\mathrm{DO}_{2}$ rapidly decreased (0.23 remaining fraction) within $5 \mathrm{~min}$ of holding time. As the experiment proceeded, the remaining fractions of $\mathrm{DO}_{2}$ were 0.18 and 0.13 after 10 and 15 min, respectively. In the case of PATP, the retained fractions of $\mathrm{DO}_{2}$ were 0.08 and 0.06 after 10 and 15 min, respectively. A close examination of the $k_{l}$ values (Table 1) indicated that more oxygen was consumed by those samples with added AA and treated at $0.1 \mathrm{MPa} / 120{ }^{\circ} \mathrm{C}\left(0.366 \mathrm{~min}^{-1}\right)$ compared with those samples with added AA and treated at $600 \mathrm{MPa} / 120{ }^{\circ} \mathrm{C}\left(0.081 \mathrm{~min}^{-1}\right)$. In the presence of oxygen, the AA is converted to dehydroascorbic acid (DHA) by abstracting a proton, making it unstable [30]. At the beginning of the holding time, the AA might be acting as a scavenging agent due to its relatively high initial concentration $\left(0.5 \mathrm{~g} \mathrm{~kg}^{-1}\right)$ [31]. Moreover, the initial molar concentration of the AA $\left([\mathrm{AA}]_{\mathrm{o}}=\right.$ $2.8 \mathrm{mM})$ is four-times higher than the initial molar concentration of oxygen $\left(\left[\mathrm{DO}_{2}\right]_{\mathrm{o}}=0.68 \mathrm{mM}\right)$. A molar ratio of at least $2\left(\mathrm{AA} / \mathrm{O}_{2}\right)$ was reported to protect other compounds from oxidation [4]. When most of the $\mathrm{DO}_{2}$ was consumed, the oxidation of CLA was evident. One possible reason is that the AA can be ionized when pressure is applied to form ascorbate, which is more reactive than the AA. Both compounds oxidize to produce hydrogen peroxide, which might trigger the late oxidation of CLA [32].

\subsection{Cysteine}

The remaining CLA in samples with added cysteine (Cyst) is shown in Table 2. At $0.1 \mathrm{MPa}$ and $120{ }^{\circ} \mathrm{C}$, the retained fractions of CLA were 0.59 and 0.56 after 10 and $15 \mathrm{~min}$ of holding time, respectively. An investigation showed that Cyst can be used to inhibit the formation of off-flavor compounds in UHT milk [29]. At $600 \mathrm{MPa}$, the retained fractions of CLA were 0.73 and 0.70 after 10 and $15 \mathrm{~min}$, respectively. The combination of Cyst and pressure yielded a higher remaining fraction of CLA compared with the control treatment $(0.1 \mathrm{MPa})$. Likewise, Cyst inhibited the formation of aldehydes and hydrogen sulfide in milk pressurized at $655 \mathrm{MPa}$ and heated at $75^{\circ} \mathrm{C}$ for $10 \mathrm{~min}$ [29].

On the other hand, the $\mathrm{DO}_{2}$ rapidly decreased with increasing holding time at $0.1 \mathrm{MPa}$, resulting in a value of 0.05 after 15 min of holding time. At $600 \mathrm{MPa}$, the $\mathrm{DO}_{2}$ fraction was considerable higher than that at $0.1 \mathrm{MPa}$ with a value of 0.42 after $15 \mathrm{~min}$ of holding time. In the presence of oxygen, Cyst reacts with the hydroxyl radical to form sulfonic acid [30]. This could be the reason for the substantial reduction in the $\mathrm{DO}_{2}$ fraction observed at $0.1 \mathrm{MPa}$ (Table 2). The $k_{1}$ values reported in Table 1 at 600 and $0.1 \mathrm{MPa}$ were 0.030 and $0.194 \mathrm{~min}^{-1}$, respectively, meaning that a small amount of oxygen was needed to oxidize CLA. Cyst has the ability to quench oxygen. An investigation on the reactivity of the $\mathrm{O}_{2}$ with amino acids showed that oxidation of amino acids was the predominant reaction rather than $\mathrm{O}_{2}$ quenching. Cyst possesses a thiol group, which is believed to act as an antioxidant by donating hydrogen to neutralize free radicals [33]. The ability of Cyst to quench free radicals depends on the state of protonation of the 
functional group [34]. An investigation on the oxidation of milk fat with different amino acids added showed that a non-protonated $\left(\mathrm{NH}_{2}\right)$ amino group, such as Cyst, inhibited the oxidation [35]. In PATP experiments, the reaction system suffers a temporary and reversible modification in the $\mathrm{pH}$, which might change the reaction mechanism [36].

Table 2. Changes in conjugated linoleic acid (CLA) and dissolved oxygen $\left(\mathrm{DO}_{2}\right)$ in CLA-enriched milk added with either cysteine, caffeic acid or catechin and treated at $120^{\circ} \mathrm{C}$ and 0.1 or $600 \mathrm{MPa}$.

\begin{tabular}{|c|c|c|c|c|c|c|}
\hline \multirow{3}{*}{$\begin{array}{c}\text { Holding } \\
\text { time } \\
\text { (min) }\end{array}$} & \multicolumn{6}{|c|}{ Normalized retention of conjugated linoleic acid (CLA) } \\
\hline & \multicolumn{2}{|c|}{ Cysteine } & \multicolumn{2}{|c|}{ Caffeic acid } & \multicolumn{2}{|c|}{ Catechin } \\
\hline & $0.1 \mathrm{MPa}$ & $600 \mathrm{MPa}$ & $0.1 \mathrm{MPa}$ & $600 \mathrm{MPa}$ & 0.1 MPa & $600 \mathrm{MPa}$ \\
\hline 0 & $1.00 \pm 0.00 \mathrm{a}$ & $1.00 \pm 0.00 \mathrm{a}$ & $1.00 \pm 0.00 \mathrm{a}$ & $1.00 \pm 0.00 \mathrm{a}$ & $1.00 \pm 0.00 \mathrm{a}$ & $1.00 \pm 0.00 \mathrm{a}$ \\
\hline 1 & $0.73 \pm 0.03 b$ & $0.81 \pm 0.03 b$ & $0.91 \pm 0.03 \mathrm{a}$ & $0.74 \pm 0.03 b$ & $0.95 \pm 0.03 b$ & $0.87 \pm 0.03 b$ \\
\hline 5 & $0.63 \pm 0.02 \mathrm{c}$ & $0.72 \pm 0.02 c$ & $0.79 \pm 0.02 b$ & $0.71 \pm 0.02 \mathrm{c}$ & $0.77 \pm 0.02 \mathrm{c}$ & $0.81 \pm 0.02 \mathrm{c}$ \\
\hline 10 & $0.59 \pm 0.03 \mathrm{~d}$ & $0.73 \pm 0.03 \mathrm{~cd}$ & $0.70 \pm 0.02 c$ & $0.71 \pm 0.03 c$ & $0.69 \pm 0.02 d$ & $0.79 \pm 0.03 c$ \\
\hline 15 & $0.56 \pm 0.02 \mathrm{e}$ & $0.70 \pm 0.03 d$ & $0.69 \pm 0.02 \mathrm{c}$ & $0.66 \pm 0.03 \mathrm{~d}$ & $0.39 \pm 0.02 \mathrm{e}$ & $0.75 \pm 0.03 \mathrm{~d}$ \\
\hline \multirow{3}{*}{$\begin{array}{c}\text { Holding } \\
\text { time } \\
\text { (min) }\end{array}$} & \multicolumn{6}{|c|}{ Normalized dissolved oxygen $\left(\mathrm{DO}_{2}\right)$} \\
\hline & \multicolumn{2}{|c|}{ Cysteine } & \multicolumn{2}{|c|}{ Caffeic acid } & \multicolumn{2}{|c|}{ Catechin } \\
\hline & $0.1 \mathrm{MPa}$ & $600 \mathrm{MPa}$ & 0.1 MPa & $600 \mathrm{MPa}$ & 0.1 MPa & $600 \mathrm{MPa}$ \\
\hline 0 & $1.00 \pm 0.00 \mathrm{a}$ & $1.00 \pm 0.00 \mathrm{a}$ & $1.00 \pm 0.00 \mathrm{a}$ & $1.00 \pm 0.00 \mathrm{a}$ & $1.00 \pm 0.00 \mathrm{a}$ & $1.00 \pm 0.00 \mathrm{a}$ \\
\hline 1 & $0.13 \pm 0.02 b$ & $0.79 \pm 0.03 b$ & $0.88 \pm 0.03 b$ & $0.78 \pm 0.03 b$ & $0.78 \pm 0.02 b$ & $0.71 \pm 0.03 b$ \\
\hline 5 & $0.11 \pm 0.03 \mathrm{c}$ & $0.64 \pm 0.01 \mathrm{c}$ & $0.54 \pm 0.01 \mathrm{c}$ & $0.65 \pm 0.01 \mathrm{c}$ & $0.65 \pm 0.03 c$ & $0.30 \pm 0.04 c$ \\
\hline 10 & $0.11 \pm 0.01 \mathrm{c}$ & $0.61 \pm 0.03 d$ & $0.29 \pm 0.03 d$ & $0.56 \pm 0.02 \mathrm{~d}$ & $0.56 \pm 0.01 d$ & $0.14 \pm 0.03 \mathrm{~d}$ \\
\hline 15 & $0.05 \pm 0.02 \mathrm{~d}$ & $0.42 \pm 0.04 \mathrm{e}$ & $0.25 \pm 0.02 \mathrm{e}$ & $0.18 \pm 0.03 \mathrm{e}$ & $0.18 \pm 0.02 \mathrm{e}$ & $0.09 \pm 0.03 \mathrm{e}$ \\
\hline
\end{tabular}

Means \pm standard deviation $(n=3)$; columns with different letters (a-f) are significantly different $(p<0.05)$.

\subsection{Phenolic Antioxidants}

Tables 2 and 3 show the retention of CLA in milk added with different phenolic antioxidants. The highest retention fraction of CLA in milk was obtained after adding CAF (0.69), followed by TAN (0.64), CUM (0.43), CAT (0.39) and GA (0.36) after $15 \mathrm{~min}$ of holding time at $120{ }^{\circ} \mathrm{C} / 0.1 \mathrm{MPa}$. On the other hand, after $15 \mathrm{~min}$ and $120{ }^{\circ} \mathrm{C} / 600 \mathrm{MPa}$, the highest retention fraction was obtained with GA (0.85), followed by CAT (0.75), CAF (0.66) CUM (0.63) and TAN (0.62). In general, phenolic antioxidants possess the ability to inhibit the autoxidation of lipids by trapping intermediate radicals and quenching dissolved oxygen due to their low ionization potential [37]. Tables 2 and 3 also show the changes in $\mathrm{DO}_{2}$ in milk with added phenolic antioxidants. After $15 \mathrm{~min}$ of holding time at $120{ }^{\circ} \mathrm{C} / 0.1 \mathrm{MPa}$, the consumption of $\mathrm{DO}_{2}$ was larger in those samples with added TAN and GA (0.11), followed by CAT (0.18), CUM (0.21) and CAF (0.25). After $15 \mathrm{~min}$ of holding time at $120^{\circ} \mathrm{C} / 600 \mathrm{MPa}$, the consumption of $\mathrm{DO}_{2}$ was greater in samples with added CUM (0.10), CAT (0.11) and GA (0.11), followed by TAN (0.13) and CAF (0.18). Upon thermal treatment, TAN is hydrolyzed and formed gallic acid and polygalloyls, which enhanced the antioxidant capacity. An investigation on the oxidation of soybean oil showed that the addition of hydrolyzed TAN extended the oxidation induction period by up to $84 \%$ compared with the control treatment [35]. These authors thermally treated TAN $\left(121{ }^{\circ} \mathrm{C}\right.$ up to $60 \mathrm{~min}$ ) and found that $15 \mathrm{~min}$ of thermal treatment was enough to hydrolyze TAN. The ability of TAN 
to react with oxygen was demonstrated during the oxidation of ascorbate in the presence of copper, where TAN not only reacted with oxygen, but also chelated metal ions, delaying the oxidation process [38]. In PATP-treated samples, the $k_{1}$ value was $0.069 \mathrm{~min}^{-1}$, suggesting a change in the reaction mechanism induced by pressure in the presence of TAN (Table 1).

The value of $k_{1}$ (Table 1) in milk with CAF addition obtained at PATP was $0.041 \mathrm{~min}^{-1}$, indicating that the addition of CAF enhanced the retention of CLA. In the case of samples added with CAT, the $k_{1}$ values were 0.051 and $0.139 \mathrm{~min}^{-1}$ at 600 and $0.1 \mathrm{MPa}$, respectively (Table 1). The $k_{1}$ values indicated that a significant amount of oxygen was needed to oxidize CLA. For those samples added with GA, the $k_{1}$ values were 0.092 and $0.150 \mathrm{~min}^{-1}$ at 600 and $0.1 \mathrm{MPa}$, respectively. Finally, those samples added with CUM yielded $k_{1}$ values of 0.042 and $0.118 \mathrm{~min}^{-1}$ at 600 and $0.1 \mathrm{MPa}$, respectively. During pressure treatment, free phenols are probably ionized, and therefore, their ability to quench oxygen is significantly enhanced. Phenols are susceptible to ionization by pressure due to charge delocalization between the oxygen and aromatic ring, yielding molar activation volumes between -8 and $-20 \mathrm{~cm}^{3} \mathrm{~mol}^{-1}$ [37]. Phenols form hydrogen bonds with surrounding molecules. Free phenols, on the other hand, are likely to be ionized, and the donated proton rapidly neutralizes the free radicals. In PATP, the use of phenolic antioxidants not only enhances the retention of CLA, but also quenches oxygen, which avoids isomerization, therefore protecting the biological activity of CLA.

Table 3. Changes in conjugated linoleic acid (CLA) and dissolved oxygen $\left(\mathrm{DO}_{2}\right)$ in CLA-enriched milk added with either gallic acid, $p$-coumaric acid or tannic acid and treated at $120{ }^{\circ} \mathrm{C}$ and 0.1 or $600 \mathrm{MPa}$.

\begin{tabular}{|c|c|c|c|c|c|c|}
\hline \multirow{3}{*}{$\begin{array}{c}\text { Holding } \\
\text { time } \\
\text { (min) }\end{array}$} & \multicolumn{6}{|c|}{ Normalized retention of conjugated linoleic acid (CLA) } \\
\hline & \multicolumn{2}{|c|}{ Gallic acid } & \multicolumn{2}{|c|}{$p$-Coumaric acid } & \multicolumn{2}{|c|}{ Tannic acid } \\
\hline & $0.1 \mathrm{MPa}$ & $600 \mathrm{MPa}$ & $0.1 \mathrm{MPa}$ & $600 \mathrm{MPa}$ & $0.1 \mathrm{MPa}$ & $600 \mathrm{MPa}$ \\
\hline 0 & $1.00 \pm 0.00 \mathrm{a}$ & $1.00 \pm 0.00 \mathrm{a}$ & $1.00 \pm 0.00 \mathrm{a}$ & $1.00 \pm 0.00 \mathrm{a}$ & $1.00 \pm 0.00 \mathrm{a}$ & $1.00 \pm 0.00 \mathrm{a}$ \\
\hline 1 & $0.69 \pm 0.03 b$ & $0.98 \pm 0.02 b$ & $0.91 \pm 0.03 b$ & $0.87 \pm 0.03 b$ & $0.91 \pm 0.03 b$ & $0.78 \pm 0.03 b$ \\
\hline 5 & $0.61 \pm 0.02 \mathrm{c}$ & $0.94 \pm 0.02 c$ & $0.76 \pm 0.04 \mathrm{c}$ & $0.75 \pm 0.02 c$ & $0.78 \pm 0.02 \mathrm{c}$ & $0.76 \pm 0.02 c$ \\
\hline 10 & $0.51 \pm 0.02 \mathrm{~d}$ & $0.89 \pm 0.03 d$ & $0.53 \pm 0.02 \mathrm{~d}$ & $0.72 \pm 0.03 d$ & $0.75 \pm 0.02 d$ & $0.72 \pm 0.03 \mathrm{~d}$ \\
\hline 15 & $0.36 \pm 0.02 \mathrm{e}$ & $0.85 \pm 0.03 \mathrm{e}$ & $0.43 \pm 0.03 \mathrm{e}$ & $0.63 \pm 0.03 \mathrm{e}$ & $0.64 \pm 0.02 \mathrm{e}$ & $0.62 \pm 0.03 \mathrm{e}$ \\
\hline \multirow{3}{*}{$\begin{array}{c}\text { Holding } \\
\text { time } \\
\text { (min) }\end{array}$} & \multicolumn{6}{|c|}{ Normalized dissolved oxygen $\left(\mathrm{DO}_{2}\right)$} \\
\hline & \multicolumn{2}{|c|}{ Gallic acid } & \multicolumn{2}{|c|}{$\rho$-Coumaric acid } & \multicolumn{2}{|c|}{ Tannic acid } \\
\hline & $0.1 \mathrm{MPa}$ & $600 \mathrm{MPa}$ & 0.1 MPa & $600 \mathrm{MPa}$ & $0.1 \mathrm{MPa}$ & $600 \mathrm{MPa}$ \\
\hline 0 & $1.00 \pm 0.00 \mathrm{a}$ & $1.00 \pm 0.00 \mathrm{a}$ & $1.00 \pm 0.00 \mathrm{a}$ & $1.00 \pm 0.00 \mathrm{a}$ & $1.00 \pm 0.00 \mathrm{a}$ & $1.00 \pm 0.00 \mathrm{a}$ \\
\hline 1 & $0.18 \pm 0.03 b$ & $0.68 \pm 0.02 b$ & $0.84 \pm 0.02 b$ & $0.47 \pm 0.03 b$ & $0.63 \pm 0.03 b$ & $0.27 \pm 0.03 b$ \\
\hline 5 & $0.17 \pm 0.02 b$ & $0.41 \pm 0.04 \mathrm{c}$ & $0.27 \pm 0.04 \mathrm{c}$ & $0.18 \pm 0.01 \mathrm{c}$ & $0.33 \pm 0.02 c$ & $0.21 \pm 0.01 \mathrm{c}$ \\
\hline 10 & $0.13 \pm 0.02 c$ & $0.12 \pm 0.03 d$ & $0.23 \pm 0.03 d$ & $0.11 \pm 0.02 \mathrm{~d}$ & $0.30 \pm 0.03 d$ & $0.19 \pm 0.02 \mathrm{~d}$ \\
\hline 15 & $0.11 \pm 0.02 \mathrm{c}$ & $0.11 \pm 0.03 \mathrm{~d}$ & $0.21 \pm 0.02 \mathrm{e}$ & $0.10 \pm 0.02 \mathrm{~d}$ & $0.11 \pm 0.02 \mathrm{e}$ & $0.13 \pm 0.02 \mathrm{e}$ \\
\hline
\end{tabular}

Means \pm standard deviation $(n=3)$; columns with different letter $(\mathrm{a}-\mathrm{f})$ are significantly different $(p<0.05)$.

\subsection{Different Concentrations of Catechin and Gallic Acid}

An additional set of experiments were conducted using different concentrations of CAT and GA ( 0 , 100, 200, 300 and $500 \mathrm{mg} \mathrm{kg}^{-1}$, Figure 3). The samples were treated at $120{ }^{\circ} \mathrm{C}$ for $15 \mathrm{~min}$ at either 0.1 or $600 \mathrm{MPa}$. Using catechin and gallic acid, better CLA retention was obtained at $600 \mathrm{MPa}$ than at 
0.1 MPa. In the case of milk with added CAT and treated at $0.1 \mathrm{MPa}$ (Figure 3a), the retention of CLA was enhanced from 0.27 to 0.44 as the concentration increased up to $500 \mathrm{mg} \mathrm{kg}^{-1}$. At $600 \mathrm{MPa}$, the retention of CLA was remarkably enhanced, reaching values of 0.82 when $500 \mathrm{mg} \mathrm{kg}^{-1}$ of CAT was added. Similarly, the combined effect of $600 \mathrm{MPa}$ and GA resulted in a retention of 0.85 , which is considerably higher than that obtained at $0.1 \mathrm{MPa}(0.41)$. Catechin has been used for delaying non-enzymatic browning in UHT milk [39]. It was demonstrated that a concentration of $0.1 \mathrm{mmol} \mathrm{L}^{-1}$ was enough to inhibit the browning of UHT non-enriched milk at $145{ }^{\circ} \mathrm{C}$ for $15 \mathrm{~s}$ during prolonged storage up to 36 days. More importantly, consumer sensory analysis showed no difference with respect to the control samples (samples without added catechin) [39]. In our study, a similar concentration of CAT was used (500 $\mathrm{mg} \mathrm{kg}^{-1}, 0.17 \mathrm{mmol} \mathrm{L}^{-1}$ ); therefore, changes in sensory perception due to the addition of CAT are not expected, but further research is needed to confirm this assumption.
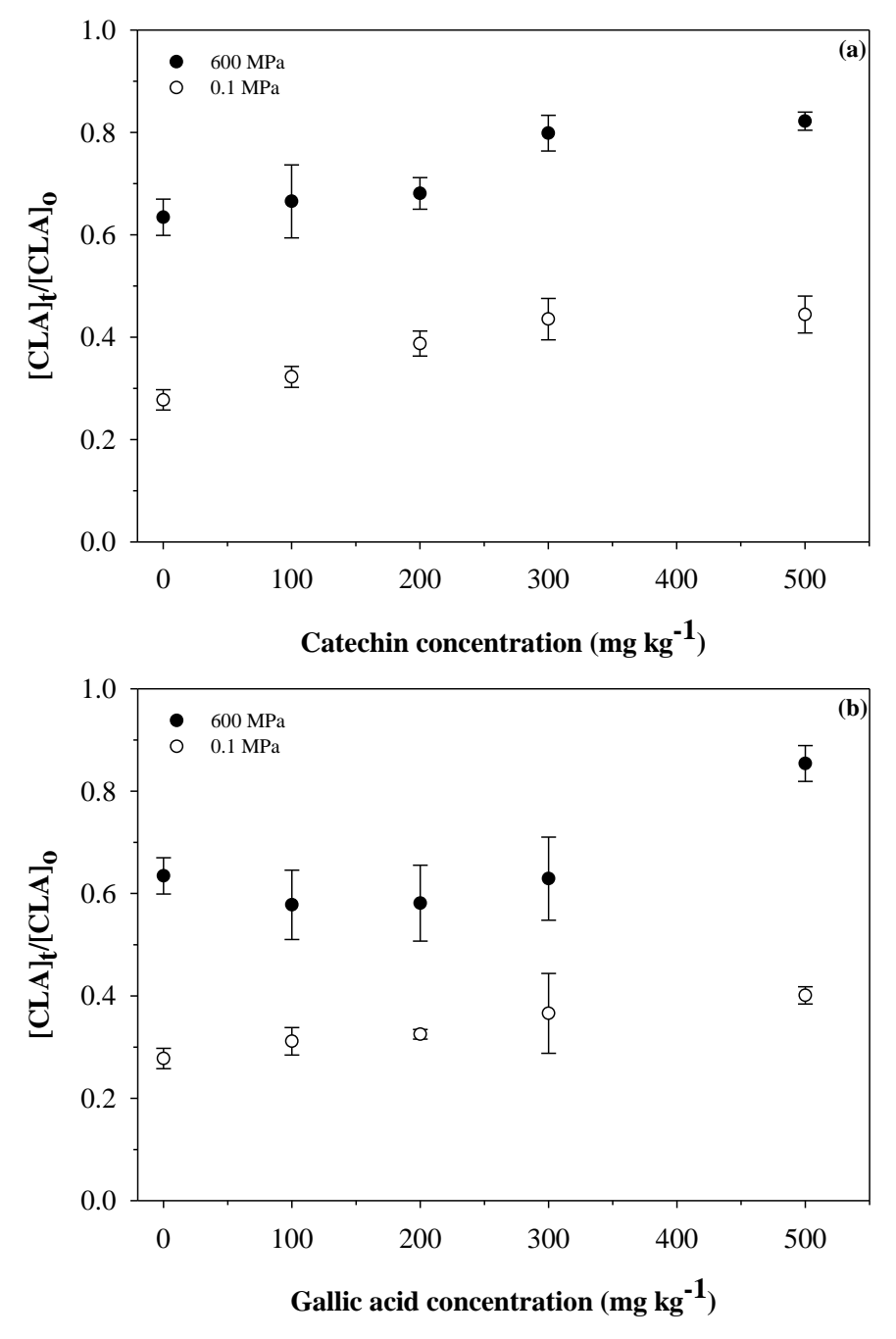

Figure 3. Effect of the concentration of (a) catechin and (b) gallic acid on the CLA retention in CLA-enriched milk treated at $120^{\circ} \mathrm{C}$ for $15 \mathrm{~min}$ at either 0.1 or $600 \mathrm{MPa}$.

\subsection{Possible Reaction Mechanisms of Phenolic Antioxidants}

The use of phenolic antioxidants $\left(500 \mathrm{mg} \mathrm{kg}^{-1}\right)$ in combination with high pressure yielded a high retention of CLA ( $~ 85 \%$ in the case of GA), even at a prolonged holding time of $15 \mathrm{~min}$. In general, the 
effectiveness of a given antioxidant is usually associated with the structure-function relation, in which the number of $-\mathrm{OH}$ groups are related to its effectiveness. In the case of the retention of CLA upon pressure, the number of $-\mathrm{OH}$ groups did not reflect the antioxidant effectiveness. While TAN possess $27-\mathrm{OH}$ groups in its structure, the retained normalized CLA was only 0.633. In contrast, GA and CAT with four and five $-\mathrm{OH}$ groups, respectively, yielded higher retention values $(>0.75)$ than that obtained using TAN. The stability of antioxidants played an important role in enhancing the retention of CLA. The GA is considered a stable molecule, as proven by its thermogravimetric analysis, which showed that decarboxylation and further degradation started only at $260{ }^{\circ} \mathrm{C}$ [40]. A closer observation of Tables 2 and 3 revealed that the oxygen was gradually consumed while the CLA remained unchanged. Phenolic antioxidants are known for their ability to quench oxygen, preventing the initiation stage of autoxidation [34]. Table 4 shows the changes in total phenolic content for milk samples with added $500 \mathrm{mg} \mathrm{kg}^{-1}$ of GA, CAT and CAF and treated at $120{ }^{\circ} \mathrm{C} / 600 \mathrm{MPa}$.

Table 4. Normalized phenolic content in CLA-enriched milk added with different phenolic antioxidants and treated at $120^{\circ} \mathrm{C}$ and $600 \mathrm{MPa}$.

\begin{tabular}{cccc}
\hline \multirow{2}{*}{$\begin{array}{c}\text { Holding time } \\
(\text { min })\end{array}$} & \multicolumn{3}{c}{ Antioxidant added $\left(\mathbf{5 0 0} \mathbf{~ m g ~ k g}^{-\mathbf{1}}\right)$} \\
\cline { 2 - 4 } & Gallic acid & Catechin & Caffeic acid \\
\hline 0 & $1.00 \pm 0.00$ & $1.00 \pm 0.00$ & $1.00 \pm 0.00$ \\
1 & $0.94 \pm 0.02$ & $0.72 \pm 0.03$ & $0.94 \pm 0.02$ \\
5 & $0.81 \pm 0.01$ & $0.53 \pm 0.04$ & $0.81 \pm 0.01$ \\
10 & $0.61 \pm 0.02$ & $0.44 \pm 0.05$ & $0.61 \pm 0.04$ \\
15 & $0.48 \pm 0.07$ & $0.40 \pm 0.02$ & $0.48 \pm 0.05$ \\
\hline$k_{1}\left(\mathrm{~min}^{-1}\right)$ & $0.029 \pm 0.006$ & $0.078 \pm 0.005$ & $0.014 \pm 0.005$ \\
$k_{2}\left(\mathrm{~min}^{-1}\right)$ & $0.081 \pm 0.006$ & $0.051 \pm 0.019$ & $0.061 \pm 0.025$ \\
\hline
\end{tabular}

The variability of $k_{1}$ and $k_{2}$ correspond to the $95 \%$ confidence interval.

In general, the phenolic content followed a similar pattern to that observed for the $\mathrm{DO}_{2}$, reaching normalized retention values in the range of $0.40-0.48$ after $15 \mathrm{~min}$ of holding time. Table 4 also shows the apparent quenching rate constant. Interestingly, GA yielded the highest $k_{2}$ value (quenching constant rate) and the lowest $k_{1}$ value (oxidation constant rate of CLA) followed by CAT and $\mathrm{CAF}$ at $120^{\circ} \mathrm{C} / 600 \mathrm{MPa}$ up to $15 \mathrm{~min}$. The use of GA resulted in the highest CLA retention followed by CAT. It seems that GA has the ability to quench oxygen and, therefore, to delay the oxidation of CLA. Another important factor to consider is the ratio of $\mathrm{DO}_{2}$ to the antioxidant. Ratios for GA and CAT were calculated, as these antioxidants yielded the highest retention of CLA. After 10 min of holding time, ratios of 0.22 and 1.28 were obtained for GA and CAT, respectively. A ratio of $\mathrm{DO}_{2} /$ antioxidant higher than one means that the antioxidant is consumed faster than the available oxygen, indicating that there is an excess of oxygen that can further react. On the other hand, a $\mathrm{DO}_{2} /$ antioxidant ratio of less than one could be viewed as the amount of oxygen being limited with respect to the amount of antioxidant (GA). These calculated ratios further demonstrated that the use of GA significantly enhanced the retention of CLA during PATP of milk. The processing conditions of temperature, pressure and holding time not only influenced the retention of CLA, but also the effectiveness of the tested phenolic antioxidants. Further studies should determine the content of each antioxidant used after PATP treatments to evaluate its stability in the enriched milk. 


\section{Conclusions}

In the presence of oxygen, CLA was remarkably stable in samples treated with PATP compared to the control. The analysis of remaining CLA and consumed oxygen suggests that pressure-induced isomerization of CLA, which might occur through a free radical mechanism. The application of PATP in milk samples containing phenolic antioxidants enhanced the retention of CLA. Gallic acid yielded the highest retention of CLA followed by catechin. During PATP, the rate of oxygen quenching was higher than the oxidation rate of CLA, which might avoid isomerization and, therefore, preserve the biological activity of CLA. Thus, the combination of PATP and the use of phenolic antioxidants can be applied to produce milk-based beverages rich in CLA, addressing the growing demand for functional drinks.

\section{Acknowledgments}

The authors thank the Natural Sciences and Engineering Research Council of Canada (NSERC) and the Food and Health Innovation Initiative of the Faculty of Agricultural, Life and Environmental Sciences at University of Alberta for funding this project. Martinez-Monteagudo expresses his gratitude to Consejo Nacional de Ciencia y Tecnologia (CONACYT, Mexico) and Instituto de Inovacion y Transferencia Tecnologica $\left(\mathrm{I}^{2} \mathrm{~T}^{2}\right.$, Mexico) for the financial support (No. 187497).

\section{Author Contributions}

This investigation was performed by SI Martinez-Monteagudo as part of his $\mathrm{PhD}$ thesis under the supervision of MDA Saldaña.

\section{Conflicts of Interest}

The authors declare no conflict of interest.

\section{References}

1. Balasubramaniam, V.M.; Martínez-Monteagudo, S.I.; Gupta, R. Principles and application of high pressure-based technologies in the food industry. Ann. Rev. Food Sci. Tech. 2015, 6, 1-28.

2. Gupta, R.; Kopec, R.E.; Schwartz, S.J.; Balasubramaniam, V.M. Combined pressure-temperature on carotenoid retention and bioaccessibility in tomato juice. J. Agric. Food Chem. 2011, 59, 7808-7817.

3. Martinez-Monteagudo, S.I.; Saldaña, M.D.A. Chemical reactions in food systems at high hydrostatic pressure. Food Eng. Rev. 2014, 6, 105-127.

4. Oey, I.; Verlinde, P.; Hendrickx, M.E.; van Loey, A. Temperature and pressure stability of L-ascorbic acid and/or 6s 5-methyltetrahydrofolic acid: A kinetic study. Eur. Food Res. Tech. 2006, 223, 71-77.

5. Verbeyst, L.; Bogaerts, R.; van der Plancken, I.; Hendrickx, M.E.; van Loey, A. Modelling of vitamin $\mathrm{C}$ degradation during thermal and high-pressure treatments of red fruits. Food Bioprocess. Tech. 2013, 6, 1015-1023. 
6. Butz, P.; Serfert, Y.; Garcia, A.F.; Dieterich, S.; Lindauer, R.; Bognar, A.; Tauscher, B. Influence of high-pressure treatment at 25 degrees $\mathrm{C}$ and 80 degrees $\mathrm{C}$ on folates in orange juice and model media. J. Food Sci. 2004, 69, S117-S121.

7. Matser, A.A.; Krebbers, B.; van den Berg, R.W.; Bartels, P.V. Advantages of high pressure sterilisation on quality of food products. Trends Food Sci. Technol. 2004, 15, 79-85.

8. Verbeyst, L.; Oey, I.; van der Plancken, I.; Hendrickx, M.; van Loey, A. Kinetic study on the thermal and pressure degradation of anthocyanins in strawberries. Food Chem. 2010, 123, 269-274.

9. Gupta, R.; Balasubramaniam, V.M.; Schwartz, S.J.; Francis, D.M. Storage stability of lycopene in tomato juice subjected to combined pressure-heat treatments. J. Agric. Food Chem. 2010, 58, 8305-8313.

10. Martinez-Monteagudo, S.I.; Saldaña, M.D.A. Modeling the retention kinetic of conjugated linoleic acid during high-pressure sterilization of milk. Food Res. Int. 2014, 62, 169-176.

11. Sevenich, R.; Kleinstueck, E.; Crews, C.; Anderson, W.; Pye, C.; Riddellova, K.; Hradecky, J.; Moravcova, E.; Reineke, K.; Knorr, D. High-pressure thermal sterilization: Food safety and food quality of baby food puree. J. Food Sci. 2014, 79, M230-M237.

12. Cook, M.E.; Pariza, M. The role of conjugated linoleic acid (CLA) in health. Int. Dairy J. 1998, 8, 459-462.

13. Campbell, W.; Drake, M.A.; Larick, D.K. The impact of fortification with conjugated linoleic acid (CLA) on the quality of fluid milk. J. Dairy Sci. 2003, 86, 43-51.

14. Herzallah, S.M.; Humeid, M.A.; Al-Ismai, K.M. Effect of heating and processing methods of milk and dairy products on conjugated linoleic acid and trans fatty acid isomer content. J. Dairy Sci. 2005, 88, 1301-1310.

15. Martinez-Monteagudo, S.I.; Saldaña, M.D.A. Retention of bioactive lipids in heated milk: Experimental and modelling. Food Bioprod. Process. 2015, 94, 290-296.

16. Martínez-Monteagudo, S.I.; Leal-Dávila, M.; Curtis, J.M.; Saldaña, M.D.A. Oxidative stability of ultra high temperature milk enriched in conjugated linoleic acid and trans-vaccenic acid. Int. Dairy J. 2015, 43, 70-77.

17. Martinez-Monteagudo, S.I.; Saldaña, M.D.A.; Torres, J.A.; Kennelly, J.J. Effect of pressure-assisted thermal sterilization on conjugated linoleic acid (CLA) content in CLA-enriched milk. Innov. Food Sci. Emerg. Tech. 2012, 16, 291-297.

18. Bell, J.A.; Griinari, J.M.; Kennelly, J.J. Effect of safflower oil, flaxseed oil, monensin, and vitamin $\mathrm{E}$ on concentration of conjugated linoleic acid in bovine milk fat. J. Dairy Sci. 2006, 89, 733-748.

19. Rasanavagam, V.; Balasubramaniam, V.M.; Ting, E.; Sizer, C.E.; Bush, C.; Anderson, C. Compression heating of selected fatty food materials during high pressure processing. J. Food Sci. 2003, 68, 2544-2559.

20. Martinez-Monteagudo, S.I.; Saldaña, M.D.A.; Kennelly, J.J. Kinetics of non-isothermal oxidation of anhydrous milk fat rich in conjugated linoleic acid using differential scanning calorimetry. J. Therm. Anal. Calorim. 2012, 107, 973-981.

21. Singh, P.P.; Saldaña, M.D.A. Subcritical water extraction of phenolic compounds from potato peel. Food Res. Int. 2011, 44, 2452-2458. 
22. Martínez-Monteagudo, S.I.; Gänzle, M.G.; Saldaña, M.D.A. High-pressure and temperature effects on the inactivation of Bacillus amyloliquefaciens, alkaline phosphatase and storage stability of conjugated linoleic acid in milk. Innov. Food Sci. Emerg. Tech. 2014, 16, 291-297.

23. Neuman, R.C. Pressure effects as mechanistic probes of organic radical reactions. Accounts Chem. Res. 1972, 5, 381-387.

24. Neuman, R.C.; Amrich, M.J. High pressure studies. X. Activation volumes for homolysis of single bonds. J. Am. Chem. Soc. 1972, 98, 2730-2733.

25. Destaillats, F.; Angers, P. Thermally induced formation of conjugated isomers of linoleic acid. Eur. J. Lipid Sci. Tech. 2005, 107, 167-172.

26. Destaillats, F.; Angers, P. Evidence for [1,5] Sigmatropic rearrangements of CLA in heated oils. Lipids 2002, 37, 435-438.

27. Isaacs, N.S. Liquid Phase High Pressure Chemistry; John Wiley: Toronto, Canada, 1981.

28. Lindmark-Mansson, H.; Akesson, B. Antioxidative factors in milk. Br. J. Nutr. 2000, 84, S103-S110.

29. Vazquez-Landaverde, P.A.; Torres, J.A.; Qian, M.C. Effect of high-pressure-moderate-temperature processing on the volatile profile of milk. J. Agr. Food Chem. 2006, 54, 9184-9192.

30. Choe, E.; Min, D.B. Chemistry and reactions of reactive oxygen species in foods. Crit. Rev. Food Sci. Nutr. 2006, 46, 1-22.

31. Yen, G.C.; Duh, P.D.; Tsai, H.L. Antioxidant and pro-oxidant properties of ascorbic acid and gallic acid. Food Chem. 2002, 79, 307-313.

32. Chimi, H.; Cillard, J.; Cillard, P.; Rahmani, M. Peroxyl and hydroxyl radical scavenging activity of some natural phenolic antioxidants. J. Am. Oil Chem. Soc. 1991, 68, 307-312.

33. Khan, N.S.; Ahmad, A.; Hadi, S.M. Anti-oxidant, pro-oxidant properties of tannic acid and its binding to DNA. Chem-Biol. Interact. 2000, 125, 177-189.

34. Sánchez-Moreno, C.; Larrauri, J.A.; Saura-Calixto, F. Free radical scavenging capacity and inhibition of lipid oxidation of wines, grape juices and related polyphenolic constituents. Food Res. Int. 1999, 32, 407-412.

35. Kim, T.J.; Silva, J.L.; Kim, M.K.; Jung, Y.S. Enhanced antioxidant capacity and antimicrobial activity of tannic acid by thermal processing. Food Chem. 2010, 118, 740-746.

36. Huppertz, T.; Smiddy, M.A.; Vpadhyay, V.K.; Kelly, A.L. High-pressure-induced changes in bovine milk: A review. Int. J. Dairy Technol. 2006, 59, 58-66.

37. Hamann, S.D.; Linton, M. Influence of pressure on the ionization of substituted phenols. J. Chem. Soc. Faraday Trans. 1 1974, 70, 2239-2249.

38. Ohara, K.; Ichimura, Y.; Nagaoka, S. Kinetic study of singlet-oxygen quenching by caffeic acid and related phenols. Bull. Chem. Soc. Jpn. 2009, 82, 689-691.

39. Schamberger, G.P.; Labuza, T.P. Effect of green tea flavonoids on Maillard browning in UHT milk. LWT Food Sci. Technol. 2007, 40, 1410-1417.

40. Garro-Galvez, J.M.; Fechtal, M.; Riedl, B. Gallic acid as a model of tannins in condensation with formaldehyde. Thermochim. Acta 1996, 274, 149-163.

(C) 2015 by the authors; licensee MDPI, Basel, Switzerland. This article is an open access article distributed under the terms and conditions of the Creative Commons Attribution license (http://creativecommons.org/licenses/by/4.0/). 